Scientific Journal Warsaw University of Life Sciences - SGGW

Problems of World Agriculture volume 18 (XXXIII), number 4, 2018: 175-182

DOI: 10.22630/PRS.2018.18.4.108

Ewa Halicka $^{1}$, Krystyna Rejman ${ }^{2}$, Joanna Kaczorowska ${ }^{3}$

Warsaw University of Life Sciences - SGGW, Poland

\title{
Changes in EU Food Supply and the Activities of the European Platform for Action on Diet, Physical Activity and Health
}

\begin{abstract}
This paper presents the changes in food supply in selected EU Member states and average EU+ after the establishment of the European Platform for Action in the field of Diet, Physical Activity and Health in 2005. The per capita annual supply of vegetables, fruits, pulses, sugar \& sweeteners and the daily values of calories and fat are analysed based on FAO Food Balance Sheet (FBS) data. The supply of vegetables in the EU has decreased since 2005 while that of fruits, pulses and sugar \& sweeteners, as well as energy and fat have not changed significantly. The 313 voluntary commitments of Platform members, aimed at promoting healthier food choices and life styles in the region do not seem to have had a significant impact on food supply at population level. Firmer policy measures, incl. fiscal regulations are needed to support these voluntary actions. Sustainability issues should be included in the health-oriented initiatives as food choices contribute not only to the health of individuals but also of the environment as a whole.
\end{abstract}

Key words: food supply, European Union, changes, Platform, sustainable diets

JEL Classification: P46, I19, 052, Q31

\section{Introduction}

The average daily food energy supply in all European Union countries (EU+) according to FAO data has increased in the last twenty years by $100 \mathrm{kcal}$ per capita and is currently estimated at $3409 \mathrm{kcal}$ (FAO 2018). Weight problems and obesity of inhabitants are also growing at a rapid rate in most of the EU countries, an estimate of $51,6 \%$ of the adult population experiencing excess bodyweight in 2014 (Eurostat 2018). For society as a whole, this implies substantial direct and indirect costs that put a considerable strain on healthcare as well as economic and natural resources. Obesity also imposes costs in the form of lost productivity and foregone economic growth as a result of lost work days, lower productivity at work, mortality and permanent disability (Tremmel et al., 2017).

Many EU institutions, including the European Commission's Health and Food Safety Department (Directorate General SANTE) have taken steps to counteract these alarming trends. The Commission's High Level Group (HLG) on Nutrition and Physical Activity enhances contact between governments so that relevant collaboration with and between the food industry, health-oriented NGOs and policy-makers takes place. In 2005 the European

\footnotetext{
${ }^{1}$ PhD., Department of Department of Organisation and Consumption Economics, Faculty of Human Nutrition and Consumer Sciences, Nowoursynowska 159c, 02-776 Warsaw, e-mail: ewa_halicka@sggw.pl; https://orcid.org/0000-0002-0535-2115

${ }^{2}$ Dr hab., Department of Department of Organisation and Consumption Economics, Faculty of Human Nutrition and Consumer Sciences, Nowoursynowska 159c, 02-776 Warsaw,e-mail: krystyna_rejman@sggw.pl; https://orcid.org/0000-0001-8692-4383

${ }^{3}$ PhD., Department of Department of Organisation and Consumption Economics, Faculty of Human Nutrition and Consumer Sciences, Nowoursynowska 159c, 02-776 Warsaw, e-mail: joanna_kaczorowska@sggw.pl; https://orcid.org/0000-0002-8622-3912
} 
Platform for Action on Diet, Physical Activity and Health (EPAD) was launched, which led to more than 300 initiatives involving stakeholders at local, regional, national and European levels. The Common Agriculture Policy is also seen as having a potentially important role in shaping food consumption trends. However, besides supply-side school interventions there is in general a lack of further ideas on how to address nutrition through CAP (Walls et al. 2016).

\section{Aim and methodology of study}

The aim of this study is to analyse the changes in daily supply of energy and fat, as well as the annual supply of vegetables, fruits, pulses and sugar \& sweeteners in EU countries since the establishment of the European Platform for Action on Diet, Physical Activity and Health in 2005. The article also provides an overview on the voluntary efforts being made by the Platform members to promote healthy diets in the region.

The methodology focuses on comparing the changes of the average EU supply level $(\mathrm{EU}+)$ with those of four countries - United Kingdom, Belgium, Spain, France - in which the number of Platform activities undertaken is highest, and Poland. The main source of statistical data was the FAO Food Balance Sheets (FBS) database, which shows food items for human consumption, along with how it is produced, used, imported/exported, and how it benefits the society (per capita supply). Per capita values are calculated for the supply of all food commodities in kilograms per person per year and of calories, protein, and fat content per day (ESS, 2018).

FBS is a unique source for showing international trends in food supply and includes food consumption at home, outside of home and waste along the whole food chain from the production to the end-consumer. FBS estimate food consumption only from a food supply perspective and do not differentiate by diets consumed by different population groups such as children, the elderly or those from disadvantaged backgrounds (Elmadfa ed., 2009). Supply in this case describes the level of foods available for consumption and can be helpful for the formulation of both the Common Agriculture Policy and Food and Nutrition tools.

\section{EU Platform for Action on Diet, Physical Activity and Health}

The EU Platform for Action on Diet, Physical Activity and Health (EPAD) is a forum for European-level organisations, including food business companies, consumer and public health NGOs as well as scientific and professional associations (Fig. 1). Their voluntary commitments to introduce actions are aimed to support national governments in EU countries in reducing the intake of salt, saturated fat, trans fat and added sugars; increasing the consumption of fruit and vegetables; reducing the exposure to and impact on children of marketing of foods; increasing regular physical activity and reducing sedentary behavior; increasing the rates of exclusive and continued breastfeeding; and reducing diet and physical activity related inequalities (DG SANTE, 2018a).

Each year a monitoring report is released describing and assessing the activities undertaken by Platform members through ongoing commitments and structured meetings serving as a basis for improving the direction and impact of the Platform. All commitments 
are voluntary actions that aim to address the increase in obesity in EU countries, Iceland, Norway and Switzerland.

The Platform members have to agree to the process and objectives set out in the founding Platform statement of 15 March 2005 and provide detailed information on their active contributions to the Platform in one or more of the identified fields of action. In 2018 there were 32 Platform members (DG SANTE 2018b) that had at least one active commitment focusing on one of the following six activity areas:

1. Advocacy and information exchange;

2. Composition of foods (reformulation), availability of healthy food options, portion sizes;

3. Consumer information, including labeling;

4. Education, including lifestyle modification;

5. Marketing and advertising;

6. Physical activity promotion.

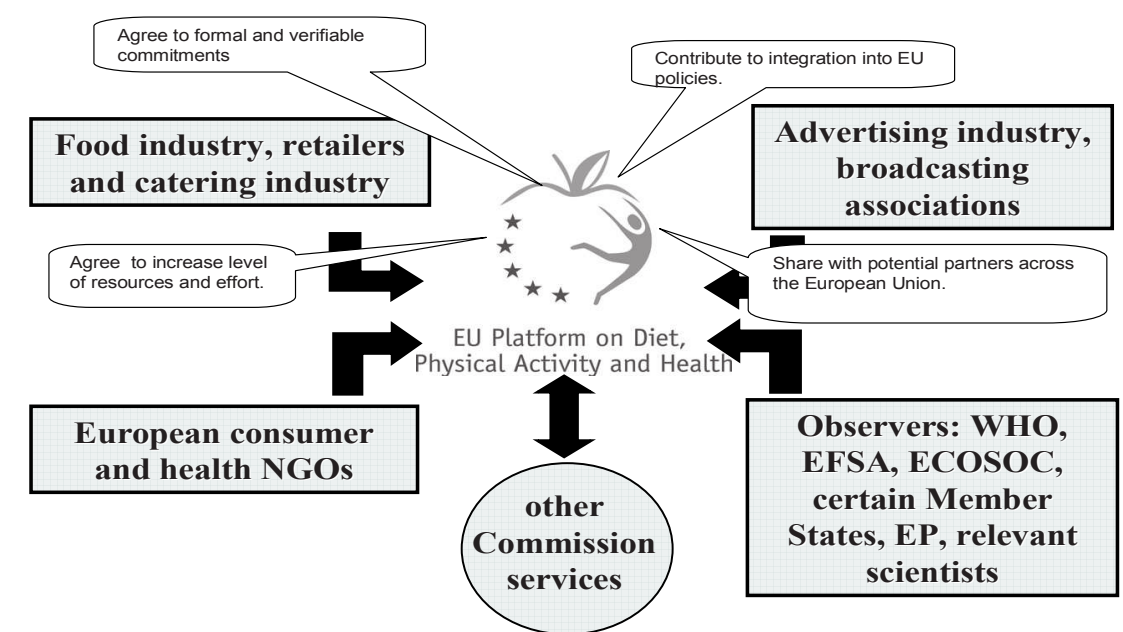

Fig 1. Structure of the European Platform for Action on Diet, Physical Activity and Health

Source: (Madelin, 2006).

The full list and detailed overview of updated commitments, is available on DG SANTE's website (EPAD database, 2018). According to this source, which includes geographical coverage, target audience and action status out of the total 313 actions carried out since 2005, 94 were still on-going in September 2018. In comparison there were 200 reported actions in 2007, 138 in 2009, 136 in 2010, 127 in 2012 and 116 in 2014. This shows that the number of active contributions of Platform members is decreasing and the initial engagement in introducing new initiatives has weakened over time. Overall, the largest number of initiatives has been carried out in the UK (203), Belgium (191), Spain (190) and France (184). Since 2005 Poland was included in 161 actions, among which 37 were educational campaigns such as: "Keep Fit", "Fruit \& Veg 4 You", "Kids Enjoy Fresh" 
(EPAD database, 2018). "Keep Fit" was carried out in Poland while the latter two covered several countries.

Out of the total 94 EPAD ongoing actions in 2018, 34 were aimed at the general public, 20 focused on children and adolescents, 13 on health professionals and 10 were aimed at policymakers. The remaining addressed the industry, educators, employees, parents and local communities. There were 68 ongoing actions in the UK, 72 in Belgium, 69 in both Spain and France and 61 in Poland.

The primary goal of the Platform - reduction of salt, saturated fat, trans fat and added sugar intake - is to be achieved mainly through changing food composition incl. product reformulation and labelling. The second goal - increase of fruit and vegetables consumption - is to be based on education and promotional campaigns financed and managed by the EPAD members. It has to be noted that according to the Platform database in September 2018,113 actions (36\% of the total) had been pledged by FoodDrinkEurope (former CIAA - Confederation of Food and Drink Industries of the EEC). Ten out of the 13 currently active initiatives aimed at changing the composition of foods (reformulation) and increasing the availability of healthy food options and portion sizes are coordinated by this organisation. One of the commitments was the development of a Framework to "scale up" efforts already underway as well as to identify and share good practices across the EU associations, especially SMEs. Eleven out of 30 actions aimed at education, incl. lifestyle modification and six out of eight aimed at information and labeling were also pledged by FoodDrinkEurope. Agricultural cooperatives and organisations (COPA COGECA) coordinated altogether 15 voluntary actions incl. an information campaign aimed at increasing fruit and vegetable consumption covering the whole region - Fruit \& Veg 4 You. The Fruit, Vegetable and Horticultural European Regions Assembly (A.R.E.F.L.H) reported one such commitment, ongoing since 2006 in 5 countries.

\section{Changes in food supply in the EU 2005-2013}

As presented in Table 1 the average daily energy supply in the European Union did not show great changes in the studied period. In both 2005 and 2013 (which is the last year for which data is available in the FAO database) it was estimated at $3409 \mathrm{kcal} / \mathrm{capita}$. The highest level of energy from total food in 2013 was observed in Belgium (3733 kcal) and the lowest in Spain $(3174 \mathrm{kcal})$.

Table 1. Daily per capita energy supply in EU+ and selected Member States 2005-2013 (kcal)

\begin{tabular}{l|lllllllll}
\hline & 2005 & 2006 & 2007 & 2008 & 2009 & 2010 & 2011 & 2012 & 2013 \\
\hline EU+ & 3409 & 3415 & 3414 & 3420 & 3419 & 3408 & 3415 & 3397 & 3409 \\
United Kingdom & 3438 & 3438 & 3417 & 3422 & 3412 & 3404 & 3417 & 3403 & 3424 \\
Belgium & 3716 & 3716 & 3713 & 3702 & 3697 & 3707 & 3720 & 3715 & 3733 \\
Spain & 3220 & 3227 & 3223 & 3208 & 3205 & 3183 & 3192 & 3173 & 3174 \\
France & 3538 & 3513 & 3466 & 3551 & 3530 & 3536 & 3514 & 3460 & 3482 \\
Poland & 3370 & 3353 & 3364 & 3346 & 3418 & 3413 & 3443 & 3443 & 3451 \\
\hline
\end{tabular}

Source: (FAOSTAT, 2018). 
Energy supply in the studied countries was above the EU average in all the years, except for Spain and Poland. The energy supply decreased slightly in France and the UK however still remained higher than the EU+ average. The biggest decrease took place in Spain. Poland, like Belgium, was characterised by a growing supply trend, which reached the EU+ average in 2009 and surpassed it in the years 2010-2013.The amount of energy from animal products decreased slightly in the EU+ from $1007 \mathrm{kcal}$ in 2005 to $978 \mathrm{kcal}$ in 2013 , constituting $29,6 \%$ and $28,7 \%$ of the total energy supplies.

The average fat supply quantity was stable and was estimated in EU+ at circa 140 grams per person per day (Table 2). In the studied period Poland was the only country in which fat supply was lower than the EU average in all years, although it increased from 113 to almost 120 grams in 2013. Belgium and France had the highest fat supply level among the studied countries - oscillating around 160 grams per capita per day. France and the UK levels were closer to and slightly higher than the EU average.

Table 2. Daily per capita supply of fat in EU+ (on average) and selected Member States 2005-2013 (grams)

\begin{tabular}{l|rcccccccc}
\hline & 2005 & 2006 & 2007 & 2008 & 2009 & 2010 & 2011 & 2012 & 2013 \\
\hline EU+ & 138 & 140 & 140 & 141 & 140 & 141 & 140 & 140 & 139 \\
United Kingdom & 139 & 147 & 140 & 140 & 139 & 142 & 138 & 138 & 138 \\
Belgium & 163 & 163 & 165 & 162 & 159 & 161 & 167 & 161 & 162 \\
Spain & 145 & 144 & 147 & 144 & 144 & 144 & 144 & 143 & 143 \\
France & 162 & 162 & 160 & 167 & 165 & 163 & 161 & 157 & 159 \\
Poland & 113 & 112 & 111 & 112 & 116 & 117 & 118 & 117 & 119 \\
\hline
\end{tabular}

Source: (FAOSTAT, 2018).

Despite many actions aimed at increasing the consumption of vegetables and fruits in the voluntary EPAD initiatives and the CAP-supported School Fruit Scheme - implemented in all EU except the UK, Sweden and Finland - the average supply of vegetables in EU+ decreased in the studied period from 120,6 kg in 2005 to 109,4 kg in 2013.

Table 3. Annual supply of vegetables in EU+ (on average) and selected Member States 2005-2013 (kg per capita)

\begin{tabular}{l|rcccccccc}
\hline & 2005 & 2006 & 2007 & 2008 & 2009 & 2010 & 2011 & 2012 & 2013 \\
\hline EU+ & 120,6 & 116,4 & 116,6 & 115,9 & 121,7 & 114,1 & 115,6 & 111,2 & 109,4 \\
United Kingdom & 95,9 & 93,4 & 91,6 & 92,9 & 88,7 & 92,8 & 96,9 & 92,9 & 96,9 \\
Belgium & 124,6 & 122,6 & 129,1 & 129,2 & 128,9 & 117,1 & 129,2 & 130,3 & 136,4 \\
Spain & 155,8 & 147,0 & 154,7 & 145,4 & 158,4 & 140,5 & 125,5 & 126,2 & 119,2 \\
France & 104,2 & 97,6 & 98,2 & 100,8 & 105,6 & 103,1 & 99,5 & 98,3 & 97,3 \\
Poland & 114,9 & 112.9 & 127,2 & 113,1 & 126,1 & 113,6 & 129,4 & 119,8 & 107,7
\end{tabular}

Source: (FAOSTAT 2018).

The lowest annual supply of vegetables (below $100 \mathrm{~kg} / \mathrm{year}$ in 2013) was noted in France and the UK, lowest in $2006(97,6 \mathrm{~kg})$ and 2009 (88,9 kg), appropriately. Belgium was the only Member State among those analysed in which vegetable supply increased, with this change starting to take place in 2011.

According to FBS data the annual per capita supply of pulses - which in the FAO classification constitute a separate category of foods incl. peas, lentils and beans - remained relatively stable in the region, oscillating between 2,61 and 2,77 $\mathrm{kg}$ in EU+ (Tab. 4). 
Unsurprisingly the highest supply level of pulses was observed in Spain, in some years double the EU+ average. It must be underlined that pulses, which are very high in protein and fibre and low in fat. are also nitrogen-fixing crops that improve the environmental sustainability of annual cropping systems.

Table 4. Annual supply of pulses in EU+ (on average) and selected Member States 2005-2013 (kg per capita)

\begin{tabular}{l|rrrrrrrrr}
\hline & 2005 & 2006 & 2007 & 2008 & 2009 & 2010 & 2011 & 2012 & 2013 \\
\hline EU+ & 2,64 & 2,75 & 2,78 & 2,71 & 2,67 & 2,74 & 2,61 & 2,68 & 2,77 \\
United Kingdom & 2,98 & 2,85 & 3,02 & 2,74 & 2,91 & 2,97 & 2,40 & 3,14 & 3,45 \\
Belgium & 2,14 & 2,18 & 2,37 & 2,28 & 2,30 & 2,23 & 2,12 & 2,67 & 2,48 \\
Spain & 4,61 & 5,77 & 5,79 & 6,41 & 5,70 & 5,20 & 5,28 & 5,42 & 5,31 \\
France & 1,97 & 1,91 & 1,85 & 1,80 & 1,71 & 1,91 & 2,00 & 1,85 & 1,86 \\
Poland & 1,63 & 1,73 & 2,20 & 1,67 & 1,76 & 2,09 & 2,09 & 2,02 & 1,84 \\
\hline
\end{tabular}

Source: (FAOSTAT 2018)

The supply of fruits in 2005-2013 (total, excluding wine) in EU+ showed a slight decrease (by $1 \mathrm{~kg} /$ capita) from $105 \mathrm{~kg}$ to $104 \mathrm{~kg}$ (Tab. 5). The most significant change took place in Spain, where supply fell systematically from $100 \mathrm{~kg}$ to $72,2 \mathrm{~kg}$ in 2013 . The supply of fruits remained highest in the UK (127,4 kg in 2013) and France (114,3 kg) however in Spain, Belgium and Poland the supply level was lower than EU+. Fruit supply increased in Poland, reaching 60,2 kg in 2013 per capita per year, compared to 51,2 kg in 2005.

Table 5. Annual supply of fruits in EU+ (on average) and selected Member States 2005-2013 (kg per capita)

\begin{tabular}{l|rcccccccc}
\hline & 2005 & 2006 & 2007 & 2008 & 2009 & 2010 & 2011 & 2012 & 2013 \\
\hline EU+ & 104,7 & 107,6 & 104,3 & 105,1 & 104,1 & 99,1 & 101,3 & 98,8 & 103,7 \\
United Kingdom & 127,0 & 139,1 & 126,9 & 134,2 & 125,1 & 123,4 & 125,7 & 126,1 & 127,4 \\
Belgium & 69,3 & 87,2 & 84,1 & 90,4 & 78,1 & 70,7 & 59,8 & 61,7 & 71,4 \\
Spain & 100,2 & 107,6 & 86,4 & 97,4 & 76,6 & 79,7 & 74,9 & 66,2 & 72,2 \\
France & 112,1 & 110,9 & 116,2 & 116,3 & 115,9 & 112,9 & 113,9 & 107,9 & 114,3 \\
Poland & 51,2 & 51,7 & 45,3 & 55,1 & 54,7 & 52,4 & 53,9 & 57,6 & 60,2 \\
\hline
\end{tabular}

Source: (FAOSTAT 2018)

Table 6. Annual supply of sugar and sweeteners in EU+ (on average) and selected Member States 2005-2013 (kg per capita)

\begin{tabular}{l|rrrrrrrrr}
\hline & 2005 & 2006 & 2007 & 2008 & 2009 & 2010 & 2011 & 2012 & 2013 \\
\hline EU+ & 40,1 & 38,2 & 37,9 & 38,3 & 38,9 & 38,7 & 39,0 & 38,9 & 39,6 \\
United Kingdom & 37,6 & 33,0 & 36,1 & 36,5 & 38,8 & 36,6 & 40,1 & 38,6 & 41,3 \\
Belgium & 53,2 & 51,0 & 50,4 & 52,6 & 54,4 & 57,1 & 50,5 & 55,7 & 52,4 \\
Spain & 29,9 & 30,2 & 29,8 & 30,2 & 30,3 & 30,4 & 31,1 & 31,2 & 31,2 \\
France & 41,7 & 37,9 & 37,3 & 36,3 & 40,4 & 38,0 & 37,7 & 38,0 & 39,2 \\
Poland & 43,6 & 43,3 & 43,6 & 42,1 & 43,5 & 43,5 & 43,7 & 44,5 & 44,4 \\
\hline
\end{tabular}

Source: (FAOSTAT 2018)

The changes of 'sugar and sweeteners' per capita annual supply is presented in Tab. 6 . A significant drop in the EU average was observed in 2006 - from 40,1 kg/year to 38,2 
$\mathrm{kg} / \mathrm{year}$ - after which the level stabilized under $40 \mathrm{~kg}$. The highest supply was noted in Belgium, each year exceeding $50 \mathrm{~kg}$ (maximum in 2010, $57 \mathrm{~kg}$ ), the lowest in Spain, where the supply oscillated at 30-31 kg per capita. In the case of the UK a slight increase took place, surpassing $41 \mathrm{~kg}$ in 2003. A growing tendency was also observed in Spain and Poland.

FAO does not publish data on salt supply however it is known that the main food groups responsible for salt intake in Europe are bread and bakery products, cereal products, meat and meat products as well as cheese and dairy products. Other important groups are ready meals and soups. Bread, cereals and bakery products are the most important sources of salt in many national diets, bread alone contributing to around $20 \%$ or more of the total salt intake. According to studies the intake of salt in the WHO Europe region exceeds the population nutrient goal of 5 grams a day (Kloss, 2017).

\section{Conclusions}

Despite a quite detailed monitoring system of the 313 voluntary actions carried out by the members of the European Platform for Action on Diet, Physical Activity and Health in the period 2005-2018 few or no scientific studies have been undertaken to analyse their impact on food supply or consumption patterns at national level. International FBS data, which estimate food quantities available for consumption show that the supply changes have been multidirectional and do not represent widespread improvement across the food environment the EU.

The energy and fat supply quantity in the EU region remained relatively stable since 2005. Poland was the country in which the biggest increases were identified. No significant increases in the case of fruit (except Poland) and vegetable per capita supply in the group of presented countries was noted while the EU+ average supply of vegetables fell below 110 kg per capita. The decreasing supply levels of fruits in Spain and Belgium are especially worrying also due to the fact that in both countries the CAP-funded School Fruit Scheme had been set in place in 2009. The supply of pulses was overall low in the EU and in the light of the UN Sustainable Development Goals it would be important to add sustainability issues, such as the need to increase the role of vegetal products in daily diets to make them healthier and more sustainable.

The voluntary actions undertaken by Platform members constitute a less burdensome and less costly approach to the food and health-related policy challenges for public institutions. They are implemented and financed by the EPAD stakeholders while DG SANTE manages the meetings, database and monitoring. The industry self-regulation initiatives, concerning reformulation of products plays a big role in the rhetoric of policy debates at EU level as NGOs and industry stakeholders need a Platform to show policymakers their voluntary contributions. However the number of their actions have been decreasing in the last years. Moreover, the membership in the Platform is broadly limited to NGOs and food and advertising industry organizations. Independent research institutes should become more involved to observe and evaluate the relevance and outcomes of the reported actions.

Based on the latest WHO estimates in European Union countries, overweight affects $30-70 \%$, and obesity between $10-30 \%$ of adults. The changes in energy and fat supply, described in the article cannot be solely correlated or referenced to the obesity epidemic 
because the prevalence of overweight and obesity is determined by many factors, incl. physical activity, demographics (incl. aging) income and technological development.

The most effective strategies in changing consumption - as shown in the case of salt are those that combine product reformulation, consumer awareness and education and are supported by appropriate monitoring mechanisms (Hendriksen, 2015). Fiscal measures should also be considered to promote faster improvement. In 2018 a sugar-sweetened drink tax was introduced in the United Kingdom and Republic of Ireland, which the European Commission officially found not to constitute State aid. In Ireland the tax is estimated to yield in the region of $€ 40 \mathrm{~m}$ in a full year, however, it is expected that as industry reformulates and consumers opt for healthier options this figure will reduce over time (SSDT 2018). The obtained financial resources should be reinvested in scientific studies and educational programs aimed at promoting healthy and sustainable diets, rich in fruits, vegetables and pulses and enhance the voluntary activities conducted by EPAD members to increase their impact on food consumption trends.

\section{References}

DG SANTE (2018a). https://ec.europa.eu/health/nutrition_physical_activity/platform_en (Accessed: Aug. 2018)

DG SANTE (2018b). https:/ec.europa.eu/health/sites/health/files/nutrition_physical_activity/docs/platform members_en.pdf (Accessed: August 2018).

Elmadfa, I. ed. (2009). European Nutrition and Health Report. Forum of Nutrition, 62.

EPAD database (2018). http://ec.europa.eu/health/ph_determinants/life_style/nutrition/platform/database/dsp_.

ESS (2018). FAO Economic and Social Development Department. Food Balance Sheets http://www.fao.org/economic/ess/fbs/en/ (Accessed: June 2018).

FAOSTAT (2018). Food Balance Sheets: http://www.fao.org/faostat/en/\#compare (Accessed: August 2018)

Hendriksen, M, van Raaij, J., Geleijnse, J., Breda, J, Boshuizen, H. (2015). Health Gain by Salt Reduction in Europe: A Modelling Study. PLoS One 10(3).

Kloss, L., Meyer, J., Graeve, L., Vetter, W. (2015). Sodium intake and its reduction by food reformulation in the European Union - A review. NFS Journal, 1, 9-19.

Madelin, R. (2006). Diet, Physical Activity and Health: EU Action. CIAA Congress, Brussels. In: Halicka E., Rejman K., Kowygo B.: European Food and Drink Industry activities aimed at encouraging consumer healthy choice in: Kowrygo B. ed. (2008): Challenges and perspectives for the European food market, WULS, Warsaw, 25-36. search.cfm?CFID=477551\&CFTOKEN=92149766\&jsessionid=08a8a4388a4e 3307ca323c21537117b7b130TR (Accessed: July 2018).

SSDT (2018). https://health.gov.ie/wp-content/uploads/2016/10/INTRODUCING-A-TAX-ON-SUGARSWEET ENED-DRINKS-FINA.pdf (Accessed: August 2018).

Tremmel, M., Gerdtham, U-G., Nilsson, P., Saha, S. (2017). Economic Burden of Obesity: A Systematic Literature Review. International Journal of Environmental Research and Public Health, 14(4), doi: 10.3390/ijerph14040435.

Walls, H.L., Cornelsen, L., Lock, K., Smith, R.D. (2016). How much priority is given to nutrition and health in the EU Common Agriculture Policy? Food Policy, 59, 12-23.

For citation:

Halicka E., Rejman K., Kaczorowska J. (2018). Changes in EU Food Supply and the Activities of the European Platform for Action on Diet, Physical Activity and Health. Problems of World Agriculture, 18(4), 175-182; DOI: 10.22630/PRS.2018.18.4.108 